\title{
Under the New Form of Chinese Sports Industry Structure Optimization Research
}

\author{
Qian Yang ${ }^{1}$, Ying Liu ${ }^{2}$, Bing Zhang,* \\ ${ }^{1}$ Institute of Physical Education, Huanggang Normal University, Huangzhou 438000, Hubei, China \\ ${ }^{2}$ Graduate School of Education, Shandong Sport University, Jinan 250102, Shandong, China
}

\begin{abstract}
China's sports also in the continuous optimization of industrial structure adjustment. Social environment, economic development, political factors restrict and promote, as the development of China's sports industry structure in recent years, gradually adapt to China's national conditions, also is the development of standardization, but from the Angle of sports industrial structure research, of which there are still some places in need of improvement. Need to correct based on the understanding that they can guarantee during the process of reform and development, China's sports industry structure optimization work more scientific, ordering.
\end{abstract}

Keywords: sports industry; Industrial structure; Optimization research

\section{INTRODUCTION}

In the present China's social and economic rapid development process, to improve the comprehensive national strength also makes the per capita consumption level rising, in this process, people's lifestyle and also some changes have taken place. Especially after the 2008 Olympic Games in Beijing, a comprehensive fitness trend is unprecedented by the general public, sports excavation also makes the value of sports industry constantly, which led to the unprecedented changes have taken place in the sports industry structure [1-3]. The growth of the consumer groups, change the way of sports consumption, sports industry market demand began to change. Under this environment and opportunity, many of China's sports enterprises grasp the lifeblood of economic development, however, there are some problems, in all walks of life are worthy to be criticized [4-7]. The sports industry is no exception, however, how to correct understanding of the problem, and make a rational adjustment, so as to convert problems into experience, better applied to the construction of industry structure, is now the development of Chinese sports industry structure in the optimization process, the focus of research. In this paper, the author combines own work experience, and for the understanding of the Chinese sports industry structure adjustment, from the social environment analysis of the industrial structure optimization and adjustment direction, so as to better promote China's sports industry structure optimization.

\section{ENVELOPMENT OF SPORTS INDUSTRY}

Decide the direction of their market consumer demand. With the growth of the national spending power, the sports industry of the participated consumption, ShiWuXing consumption and the proportion of consumption increase year by year. Scientific development of an industry can promote the all-round development of an industry. In the process of market development, the sports industry joint development with other industry is a significant feature of the market economy. Contact the universality of causes in the development process of the sports industry is also led to the development of other industries, both from light industry and heavy industry development point of view, has a strong role in promoting. Among the chain effect, the rise of the sports industry for comprehensive development and balanced development of the industry, there are a lot of positive significance $[8,9]$.

The rapid development of sports industry thanks to the 2008 Beijing Olympic Games, as a populous country, China has a huge consumer base. Therefore, under such circumstances, the development of sports industry, on the market and the consumer has the absolute advantage, especially under the influence of social environment, people's understanding of sports fitness are gradually increasing, and the fostering of national policy, an increase in the number of sports infrastructure construction, the increase of the national fitness sports guiding investment and so on factors to better promote the 
development of sports industry to lay a good social environment. Therefore, the present in the development process of China's sports industry, the market prospects are clear momentum of development.

Contemporary China, during the process of sports goods consumption, consumption ability has been improved, while the per capita consumption, there is still a gap compared with developed western countries, however, from the point of total consumption, China's sports goods consumption has become the second only to America's second largest sporting goods consumption market. And, after the end of world war ii, the sports industry in developed countries is not fully formed, are in recent years, along with material life security only after having a higher spiritual pursuit. So as to make the sports goods displayed in the middle of the major events. China in recent years, in the process of the development of sports industry, both marketing and research and development of science and technology, has greatly optimized, but also has some independent research and development of high and new technology. In the optimization of China's sports industry structure, innovation and development has never stopped.

Present throughout the whole social structure and the morphology, structure, China's sports industry has a large extent on development speed increase, but the problem of development is bound to be accompanied by the optimization of industrial structure is set up on the problem for rectification, with national policy tilt, the deep understanding of national physical fitness consciousness, for sports and sports industry investment and research and development of science and technology, industry increasingly perfect management method, combination and so on factors, although in the chaoyang industry, the sports industry in China but the outlook is still worth looking forward to.

\section{STATUS QUO OF ChINA'S SPORTS INDUSTRY}

In the present process of China's sports industry development, although development speed faster, but the momentum is good, but in the present China's development of sports industry, there are still some question. In the development process of the status quo of China's sports industry, if not for a long time will become the development process of a stumbling block, therefore, correct understanding of the status quo of China's sports industry, sports industry structure optimization research for the better, has the vital significance.

\subsection{Sports Industry Market Policies}

The present structure of sports industry in China, because of the lack of a strong policy support, resulting in the sports industry, there are a lot of problems. Because of the sports industry and a deeper relationship between with the livelihood of the people. State financial support for the development of sports industry plays an important role in promoting, especially the construction of infrastructure construction and perfect, is essentially in expanding base of sports goods consumption. In this process, to participate in the construction of sports exercise increased, the proportion of social instructors will also help the ideological understanding on its more scientific construction, the process is essentially a process of the development of Chinese sports industry. But, in the actual process, due to the policy of government is not strong, and the scope of the design is relatively less, and as a direct result of the investment environment, market operation and management, etc. are not able to give full play to the market potential. Then, will also cause in the development of sports industry structure, as a result of the policy tilt superficial formal, cannot fundamentally effective play to the role of the fostering of sports industry.

\subsection{Sports Industry Structure Adjustment}

In the present structure of China's sports industry, due to a wide range of design projects, and the connection between the cross-industry increasingly close. Therefore, during the process of adjustment of industrial structure, hard to avoid can cause some blind spots, adjust and cross-industry due to problems, such as different standard between in industrial structure adjustment, more problems. In addition, there are still a lot of sports market access barriers in China, industry monopoly, lack of the benefits and all kinds of investment main body equal opportunities, leading to social capital into the sports industry the phenomenon of lack of confidence. This problem, but also among China's sports industry structure adjustment, the major problems facing, because of the involved area is broad, and also more core interest groups involved, in a certain adjustment, is bound to be due to a lot of privacy, lead to structural adjustment of certain differences with the expected effect. If the status quo of China's sports industry structure is not improved, sports economy will only reflect changes in the economic increment, impossible structural growth and the improvement of economic quality, there 
will be no more efficient large-scale and sustainable growth. In understanding process of the sports industry structure, therefore, have to put this problem into the optimization of industry to a certain comprehensive rectification.

\subsection{Industry Statistics}

Statistics for the sports industry, industry has an important guiding role for its development. Business statistics has always been a "barometer" and "barometer". Can be more accurate reflect the development of the industry, at the same time for the future of "weather" play the role of a "forecast". However, because of China's sports industry development too fast, and centralized explosion is present in the short term, therefore, industry statistics does not have a special complete statistical system. China has not yet issued national statistical standards of the sports industry and sports industry is not included in the national economy statistic system, on the basis of sports industry scale and contribution to GDP is lack of scientific basis. Therefore, in the process of China's sports industry structure optimization, lack the support of science and big data will lead to a lot of problems can't be effective. Data shows that phenomenon, through the research data, can be more profound understanding, but at present, the provinces (cities, districts) statistical results comparable with poor sports industry. In the study of Chinese sports economic value and status in industry, many scholars only qualitative analysis, not quantitative analysis, the basic data from the European and American developed country sports industry. That will lead to use to the implementation of the process, because of the politics, economy, religion, culture and lifestyle differences, such as chaos caused by the data. While the existing sports industry statistics basic cannot reflect the running status of China's sports industry has affected people's perception of the sports industry status and role. So, for an industrial structure development, will cause a lot of the industrial structure optimization of inconvenience.

\section{Thinking in Optimizing the Structure OF THE Chinese SpOrts Industry}

In the present China's sports industry structure optimization, through to the understanding of the industry status quo, as well as for understanding the present situation of industrial structure, so that in the process of industrial development problems and deficiencies, as a result, based on the development of market economy, some of the sports industry structure adjustment, to ensure the development of China's sports industry can be equally effective.

\subsection{Development of Private Enterprises and Local Government to Participate in the Sports Industry Preferential Support}

In the process of China's sports industry structure optimization, may, when necessary, with the aid of the power of the government, to build a good development for the industry development space. Because of the government's policy has an important guiding role for the development of sports industry. And policy support and tilt can fundamentally, the industrial structure optimization of a comprehensive balance. At that time with the help of the government is required to better create a good development opportunity for the sports industry. As a new sunrise industry, need the government to create a hotbed, to better promote the balanced and healthy development. During the process of development, for example, the government needs to help expand sports enterprise direct financing channel, money on sponsoring sporting events and folk sports activities enjoy certain preferential tax policy, to ensure its in process of development, money problems will not be too many restrictions, and influence the development of industry. In addition, the government can use the folk capital construction of sports venues can give similar education land policies, through physical infrastructure, to provide residents with better physical exercise field, it will directly impact on the sports goods consumption quantity, for sports market demand, is also a big boost. At the same time, local governments can use for sports, fitness, leisure clubs, places management can reduce or business tax breaks to give one to two years, management cost and preferential policies, to ensure the development of sports industry, in this way, not only can make more consumers during the process of sports fitness, have better sports guidance and services, but also can promote the development of the whole national economy. In addition, the government can by lowering the threshold of market access, actively guide the private capital and foreign capital into the fitness amusement, competition demonstration, sports training and sports service market, so as to better promote the development of China's third industry. At the same time, the government should also encourage sports service enterprise cross-regional, cross-trade and cross-ownership operation, ensure that the sports industry in process of development, has a certain reference, so as to better promote the continuous rectification, the essence of learning from each other. At the same time, the government can also come forward, promote sports service enterprise collectivization, chaining and diversified, so the sports industry structure plays an important role in promoting the overall optimization. 


\subsection{Speed Up to Set Up the Sports Industry Research and Development Funds}

And the structure of sports industry development, set up the special fund of a sports industry research, has the vital significance in the long run. In recent years, science and technology as the primary productive force in practice has been proven again and again. Therefore, in the development of sports industry. According to China's cultural industry supporting the use of funds, for projects in accordance with, based on performance, based on the industrial chain, based on the product, the government financial support as the basic principle, special sports industry development fund was established. Encourage sports innovation, promote the development of sports science and technology, is of great significance to promote the development of sports.

And the application of the special funds, will create greater value than the real funds. So, for the sports industry, is more advantageous to form a good academic atmosphere, so that more excellent sports project to be applied. Enterprise may declare the sports industry research, targeted to give funding, to the original product and pull the development of sports industry chain is bigger projects to provide special financial support. In this way, not only sports enterprises can have a positive image, to really have personal and small business and research unit technology and the lack of capital, plays an important role. On the establishment of special funds, original intention is not inconsistent with the purpose, because the innovation research of the road itself is relatively long, this process needs increasing to independent brand of sports industry development and production of capital investment, attract enterprise capital and talent. Therefore, from the long-term development perspective, the sports industry to establish a special sports scientific research funds, both from the long-term development and the construction of sports culture, has many positive effects.

\subsection{Development of Sports Industry Statistics System}

If you want to make sports have scientific and reasonable optimization of industrial structure, and also need industry big data as support. Because of big data is the best feedback for industry development, through the historical data to the lack of understanding of industry development and the problem, can also according to the data found advantages and is worthy of reference. At the same time, with the aid of big data, can also help to better develop regular sports industry development goals. Provide more data support for the sports industry structure optimization, to ensure that during the process of industry optimization, policy approach can be more scientific. So, we need to take a reason system, the development of Chinese sports industry statistics the sports economy built into the GDP statistics. In this way, the content of the large data into how social and economic development will be more accurate. The relevant state departments need to promptly formulate sports intangible assets value assessment system, establish conforms to the law of development of sports industry, scientific and feasible statistics system, lay a foundation for cultivating new pillar industry of national economy. Catalogued, through to these data, for the rapid development of the timely adjustment of industrial structure has an important guiding role.

\section{Conclusion}

Optimize the structure of the sports industry, to speed up to promote the scientific and orderly development of China's economy also has a positive role in promoting. Among the sports industry structure optimization, to adhere to market-oriented, by using the advanced science and technology and research results, to better promote the development of sports industry structure. The sports industry to the national policies and regulations, also should undertake profound study and understanding, such ability can guarantee under the background of rapid economic development, the optimization of the sports industry organization can effective play out, ensure that the value of the sports industry structure optimization can effectively implement in practice.

\section{REFERENCES}

[1] Yu Su-Mei, Yi Chun-Yan. Research on sports tourism resources connotation and development [J]. Journal of Chengdu Sport University, 2005, 31(1):26-28.

[2] Deng Feng-Lian, Yu Su-Mei, Wu Sheng-Qi. Supporting system and influence factors of the development of China's sports tourism resources [J]. Journal of Shanghai University of Sport, 2006, 30(3):35-40.

[3] Chang Jing-Liang, Xu Hong. Sports tourism and relevant concept distinction and concept definition thereof [J]. Journal of Chengdu Sport University, 2006, 32(5):24-26. 
[4] Tan Bai-Ying, Zou Rong. Development of sports tourism in China [J]. Journal of Physical Education, 2002, 9(3): 22-25.

[5] Tan Yan-Qiu, Ge Jian-Zhu. Thoughts of opportunities for Chinese current sports tourism development and exploitation of sports tourism market [J]. Journal of Shanghai University of Sport,2002, 26(5):3-4.

[6] B. Zhang, K.L. Qin, Q. Yang, Teaching Objectives and Teaching Content Point of View the Concept of Sports Teaching and the Comparison of the Chinese Sports Teaching. Int. J. Huma. Soci. Scie. Edu. 3(6), 41-45(2016).

[7] W.J. Jiang, K.L. Qin, B. Huang, F. Li, Huanggang Middle School Basketball Teaching Present Situation and Countermeasure Research. Int. J. Huma. Soci. Scie. Edu. 3(6), 51-57(2016).

[8] L. Liu, Quantitative study and analysis for English integrated teaching based on Matlab. J. Chem. Pharm. Res. 6(5), 1937-1941(2014).

[9] H. Jiang, 2014, Chinese mens basketball team development countermeasure research based on analytic hierarchy process. J. Chem. Pharm. Res. 6(5), 1929-1936(2014).

\section{AUTHORS' BIOGRAPHY}

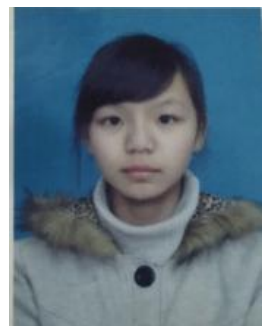

Qian Yang (1996-), female, the Han nationality, hubei wuhan, undergraduate degree, research assistant, Institute of Physical Education Huanggang Normal University grade 2014students; research interests: sports industry and sports engineering, sports management.

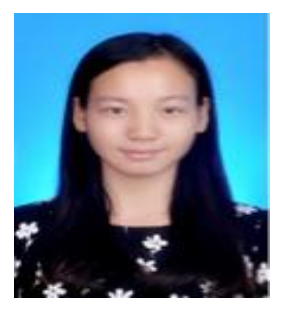

Ying Liu (1993-), female, physical education postgraduate master, Wuhan Hubei, Shandong sport university, the research direction: sports industry and physical fitness. Address: No.10600, Century Avenue, Jinan City, Shandong Provence, P.R. China (Shandong Sport University)

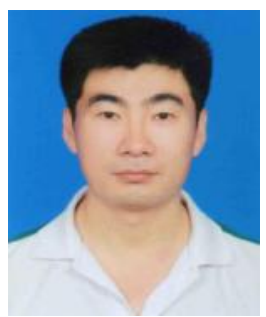

Corresponding Author: Bing Zhang(1973-), male, Mongolian, liaoning chaoyang, master degree, associate professor, research interests: sports industry and sports engineering, sports management. Address: No. 146, Xingang 2 Road, Huanggang City, Hubei Province, P.R. China (Institute of Physical Education, Huanggang Normal University). 